\title{
Research on the Organic Combination of Classical and Popular Music in College Music Teaching
}

\author{
Liaoyan Zhang \\ Weinan Normal University, Weinan, Shaanxi, 714099
}

Keywords: college music; classroom teaching; classical music; pop music

\begin{abstract}
The improvement of music literacy in college students' quality education is an important part and an important means to improve the overall quality of college students. Therefore, college music teaching should be based on the students' reality, comprehensively influence the factors influencing students' music aesthetic ability, and promote music through music teaching. The improvement of intelligence, memory and thinking ability has reached the educational function of cultivating sentiment and perfect personality. Under the background of college music education reform, the organic combination of classical and popular music is an important strategy to improve the effectiveness of college music education. Teachers explore the integration of classical and popular music in the teaching process, and achieve the ultimate goal of improving the comprehensive quality of college students. The paper mainly discusses the organic combination of classical and popular music in college music teaching.
\end{abstract}

\section{The Relationship between Classical Music and Popular Music}

So far, the industry has not made a clear definition of classical music. Most people think that classical music is a music that has been created for a long time, has been passed down to the present, and has a high musical aesthetic value. It includes not only the works created by musicians such as Mozart and Beethoven. Musical works include religious music and folk music. Western classical music reflects the grandeur and deep structure, and the playing instruments are usually fixed classical piano, organ, cello, violin, trumpet, etc., not only the complexity of the creative technology, the scale, but also give people a "orthodox serious "a feeling of. As the name suggests, popular music is popular in the present, easy to understand, and widely accepted by the masses. It reflects the emotional world of modern society and is more realistic. Analysis of popular music itself shows that its melody is short, flexible and easy. The musical instruments used include guitars, electric pianos, drums, basses, etc., and express simple emotions through a wide range of instruments.

Although the external forms of classical music and popular music are quite different, the two are consistent in the way of music rhythm control, sound field definition, harmony and other music composition, and like other music forms, they are all to convey ideas and express emotions. With the continuous development of music theory, the trend of the integration of classical music and popular music is becoming more and more obvious. Classical musicians and pop musicians are learning different music nutrients from each other and absorbing fresh music elements to promote their respective music fields. For example, incorporating some popular music elements into classical music can give people a new musical experience. For example, Richard Clayderman uses classical music to perform classical music, which is refreshing. The integration of classical music into popular music has become a trend in popular music. For example, Jay Chou's song "Nocturne" uses Chopin E major nocturne, and SHE's "Don't want to grow up" applies Mozart "fourth." The first movement of the Ten Symphony, etc., makes the pop music elements more abundant.

\section{The Significance of the Combination of Classical and Popular Music in College Music Teaching}

The integration of classical music and popular music in college music teaching can have a positive effect on college students, which is reflected in the following aspects: 
First of all, enrich the students' music knowledge system. Classical music and popular music belong to different knowledge systems, and they are also an important part of college students' music education. The combination of the two can enrich the students' music knowledge structure system and promote students' deep learning in music. Second, improve the overall quality of students. Popular music and classical music have their own characteristics, popular music style is flexible, classical music has profound connotation charm, the combination of the two can improve students' artistic appreciation level, improve students' aesthetic ability and thinking ability, thus improve students' comprehensive quality. . Finally, improve the quality of university music teaching. In the process of college music teaching, classical music and popular music are combined. The age of students determines their chances of touching pop music. Integrating classical music into pop music can stimulate students' interest in classical music and improve the quality of college music teaching.

\section{The Integration Strategy of Classical Music and Popular Music in College Music Teaching}

According to some research, college students have a special attitude towards classical music. Some students think that classical music is the sound of temples, and it is separated from students' daily life, such as opera and symphony, which will make students feel high and low. Some students think classical Music has a long history and is an old-fashioned and outdated thing. College students' thoughts are at the forefront of the times. They are more interested in the elements of personality and fashion, emphasizing their individuality. Therefore, when pop music appears, they will be chased by college students. For classical music, although they know that they have lasting value, it will bring a kind of inexplicable pressure to the students, and can't understand the connotation of classical music. Over time, it will lose interest in the study of classical music. Therefore, in the music teaching of colleges and universities, students should change their attitudes towards classical music. In the music classroom, they should infiltrate the elements of classical music, draw the distance between students and classical music, slowly eliminate students' resistance to classical music, and make the influence of the fine and silent. Students slowly accept classical music. In addition, classical music, pop music teaching and campus culture construction can be combined to develop richer music teaching resources and explore a new path for university music teaching. Encourage students to create and participate in music associations, instruct students to conduct music learning and communication with the community as a unit, and carry out various music performances, appreciations and cultural activities on campus, expand the influence of music on campus, and promote the construction of campus music culture; It is also necessary to extend music education beyond the campus, and encourage students with special skills to actively participate in music and cultural activities held in the community and local areas, such as community concerts, local cultural performances, etc., to help students master more music knowledge through artistic practice.

In the traditional college music classroom teaching, teachers usually explain the music theory knowledge first, then the music appreciation, the students passively accept the knowledge, the learning enthusiasm is low, and the classroom teaching efficiency cannot be guaranteed. The teacher reformed the current teaching model, organized some teaching activities that were more in line with the psychological characteristics of the students, and consciously merged popular music with classical music. Richard Clayderman's work is a combination of classical and popular music, so his works can be more used in music classroom teaching, such as "Jasmine", "Dream in the Dream", "Jasmine "It is the most representative work in China, which can bring the distance between classical music and students very well, and "The Wedding in Dreams" is used in "Meteor Garden" as a nostalgic idol drama, "Meteor Garden" The hit on the Internet has set off a wave of enthusiasm. One piece of piano solo of Sugi is the use of "Midden Dreams" as the background music, the teacher can play this clip in the classroom. This flexible and fun teaching activity can help students feel the charm of classical music and pop music, and improve students' music appreciation. In addition, music teaching should not be limited to the classroom. It can also provide students with more opportunities for music practice and enhance their ability to express emotion through music 
through concerts and literary evenings.

To realize the combination of classical music and popular music, it is necessary to innovate and optimize the existing music course content to deepen students' understanding and understanding of classical music and popular music, and infiltrate the two into each other in the music classroom. For example, teachers can recreate the style of classical music, integrate some elements of popular music, and improve the classroom system of college music education. The teacher should optimize the content of the music teaching materials, actively develop the school-based curriculum, enrich the content of the university music teaching, re-examine the classical music teaching materials, and integrate the popular music elements into the classical music according to the modern educational theory and the objective requirements of the development of the times, so that the students Recognizing the interoperability of classical music and popular music, it truly appreciates the profound connotation of classical music and enriches the students' musical knowledge structure. In addition to innovative music teaching content, it is also necessary to actively apply new teaching technologies, such as mobile phones, multimedia, tablet computers, etc., to innovate daily teaching methods. For example, in daily teaching, you can use multimedia to play some classical music clips and opera videos, such as the Broadway classic opera "Cat". The "Memory" inside is very familiar to many students. Playing such classic tracks can be zoomed in. The distance between students and classical music makes students accept the influence of classical music in a subtle way. Then compare it with pop singer Jolin Tsai's work "Dancing Girl" to guide students to discover the similarities and differences between the two musical forms, to help students better understand the inner feelings of the works, and to lay a solid foundation for subsequent music performances and appreciation.

Music quality education also puts forward higher requirements for the professional level and comprehensive quality of music teachers. To realize the organic combination of classical music and popular music, teachers themselves must have a comprehensive and systematic classical music knowledge system to understand and familiarize with each classic. Tracks, but also to be able to keep up with the trend of the times, appreciate and understand the trend of pop music in modern society, in order to achieve the organic combination of classical music and popular music. However, at this stage of the university music teacher team, many teachers who have studied classical music do not know much about popular music, while some music teachers have a deep understanding of popular music, but classical music is lacking in art, and both forms of music are familiar. There are very few music teachers who understand. Even some teachers' knowledge of music is not enough to control the music classroom well, so the combination of classical music and popular music cannot be guaranteed. Therefore, colleges and universities should increase the training of music teachers, not only to let them master the solid professional music knowledge, but also to improve their classroom driving ability, so as to form a high-quality music teacher team. Only in this way can the organic combination of classical music and popular music be realized smoothly. In addition, colleges and universities should provide the necessary equipment and technical support conditions for music teachers to combine classical music with popular music, such as providing music teachers with comprehensive modern teaching equipment, and enabling them to use modern equipment to carry out various tasks smoothly. Teaching activities, etc., greatly promote music teachers in the classroom with the help of modern teaching methods to gradually achieve the perfect combination of classical music and popular music in university music teaching, and make the two coordinated development in music teaching.

\section{Conclusion}

In short, with the continuous deepening of the teaching reform in colleges and universities, the requirements of the comprehensive quality of college students in the society and the state are getting higher and higher. The single popular music or classical music teaching in music teaching can no longer meet the teaching requirements. Music teaching should change the educational thought and Teaching mode, actively explore the strategy of combining classical music with popular music, reform the teaching mode, innovate teaching content, change the attitude of college students 
to classical music, and integrate the teaching of classical music and popular music into campus culture, and apply multiple channels. Help students improve their music literacy. Of course, teachers should also constantly improve their professional quality and music literacy. Colleges and universities should provide good education and training conditions for music teachers, help teachers continue to learn, promote the organic combination of classical music and popular music, and improve students through music education.

\section{References}

[1] Zhang Wenli.Study on the Combination of Classicality and Popularity in College Music Teaching[J].Journal of Chifeng College(Natural Science),2012,20:153-154.

[2] Bai Fan. Discussion on the Combination of Classical and Popular in College Music Teaching [J]. Music Time and Space, 2016, 01: 152-153.

[3] Pan Wei. On the Combination of Classicality and Popularity in College Music Teaching[J]. Northern Music, 2014, 11:209.

[4] Rao Li. Discussion on the Combination of Classicality and Popularity in College Music Teaching [J].Modern Decoration (Theory).2015, (10):279.

[5] Du Pengyu. New Thoughts on Popular Music in College Teaching [J]. Journal of Jiamusi Education College. 2010, (4): 233-234.

[6] Bi Yuhong. Classical Romantic Elements in Modern Pop Music_-Taking Jay's Music as an Example [J]. Music Time and Space (Theoretical Edition).2012, (2):55-56.

[7] Peng Jianhui, Yang Shichun, Wang Pujiang, Shi Tao. Research on Chinese Popular Music Higher Education_- Taking the School of Pop Music of Sichuan Conservatory of Music as an Example [J]. Music Exploration, 2012, (4): 116-120 